\title{
Determination of Professional Musicians' Level of Exposure to Noise: A Methodological Problem?
}

\section{Matilde A. Rodrigues}

Department of Environmental Health, Research Centre on Environment and Health, Health School of the Polytechnic Institute of Porto, Porto, Portugal

Exposure to excessive noise is frequently pointed as one of the main avoidable sources of permanent hearing loss. This problem is well documented for industrial workers; however, for other professional groups, such as musicians, the exposure profile and the procedures for its determination are not yet well established.

Previous studies focusing on musicians' exposure to noise attempted to characterize their levels of exposure [1-6] and to clarify the impact of loud music on their health [7-8]. Results emphasized that musicians are exposed to excessive sound pressure levels during the ensembles and at risk of noise-induced hearing loss (NIHL). However, when analysing different publications where musicians' level of exposure to noise was determined, the procedures adopted for these calculations or even their standardization were found to be unclear.

The problem here addressed was raised before by Behar et al. [9]. The authors, through a literature review, found that several papers lacked important information about measurement techniques, instrumentation, as well as calculation details. Furthermore, an analysis of recent publications allows to notice that different studies adopted different methods and equipment to collect data and characterize the musicians' exposure profile. Some examples are briefly described in the following. While some authors considered a single repertoire for the measurements [10], others included more than one $[2,6,10]$. Additionally, for sampling, studies included data from ensemble rehearsals [6], or from performances [2] or from both [5, 10-12]. Schmidt et al. [11] also assessed some individual rehearsals, but did not incorporate the min the determination of an $8 \mathrm{~h}$ working day exposure levels. Some authors also opted to assess a single event $[10,12]$, while others included large samples, considering data from different rehearsals and performances, as well as data collected in different venues[6]. Studies also differ in relation to the instrument used for data collation and the place where the microphone was positioned. For example, so far dosimeter microphones have been positioned on a stand [2-3] or attached to the collar or shoulder of the musicians [3,5-6]. Considering these observations, a question arises: Are these methodological differences critical to determine musicians' exposure to noise?

In fact, it is broadly recognized that determining musicians' levels of exposure to noise is not an easy task. Several variables have a significant influence on sound exposure levels, making their determination a difficult process, such as the instrument played, the repertoire (which usually changes from week to week), the number of musicians on the stage, the position in the orchestral structure and venue [1-6]. Furthermore, it is important to note that professional musicians have irregular working hours. This makes it difficult to determine the standardized levels of exposure to noise [9]. Schedules vary considerably from week to week and from musician to musician. Because of that, several studies have focused only on permanent musicians and only considered the call times. However, this raises an important question that should be considered when the risk of musicians' hearing loss is being assessed. Is it correct to consider only the time spent by the musicians in ensembles, while they spend

\section{Publication History:}

Received: November 28, 2016

Accepted: December 02, 2016

Published: December 04, 2016

\section{Keywords:}

Musicians', Barriers, Hearing loss, Exposure levels, Occupational safety, Rehearsals

so many hours practicing alone for the repertoires and to improve their performance? As an example, one can take the time of exposure considered by Russo et al. [13] and Qian et al. [5]. The authors used an annual reference of 300 working hours, the time per year that the musicians are usually contracted to play within the orchestra (ensembles). This number is too distant from the number usually used to determine noise exposure for industrial workers, i.e., $2000 \mathrm{~h}$.

Studies that consider solitary practice are scarce. However, O'Brien et al. [14] recognized that individual practice also represents an important source of professional exposure. Besides the high risk of developing NIHL during rehearsals and performances, musicians are also exposed tothis risk when practicing alone, and the risk is higher as their practice and rehearsal time increases.

Despite all the difficulties and doubts linked to the determination of noise exposure levels in professional musicians, guidelines are still scarce. General references cannot be applied directly to these settings without some adjustments. The most recent orientations from NIOSH [15] have focused on exposure limits and not on the strategies and procedures for its determination. This makes it difficult for Occupational Safety \& Health (OSH) practitioners to decide about the strategy to adopt in order to characterize the risk of NIHL. This, together with the assumption that professional musicians are often overlooked in terms of occupational safety and health practices in some countries, makes this professional group an interesting one. I believe that a hearing conservation program allied to specific guidelines will contribute to the intervention and risk evaluation quality within this professional group.

\section{References}

1. Lee J, Behar A, Kunov H, Wong W (2005) Musicians noise exposure in orchestra pit. ApplAcoust 66: 919-993.

*Corresponding Author: Prof. Matilde A. Rodrigues, Department of Environmental Health, Research Centre on Environment and Health, Health School of the Polytechnic Institute of Porto, Porto, Portugal, E-mail: mar@ess.ipp.pt

Citation: Rodrigues MA (2016) Determination of Professional Musicians'Leve of Exposure to Noise: A Methodological Problem?. Int J Community Fam Med 1: 121. doi: https://doi.org/10.15344/2456-3498/2016/121

Copyright: (C) 2016 Rodrigues. This is an open-access article distributed under the terms of the Creative Commons Attribution License, which permits unrestricted use, distribution, and reproduction in any medium, provided the original author and source are credited. 
Citation: Rodrigues MA (2016) Determination of Professional Musicians'Level of Exposure to Noise: A Methodological Problem?. Int J Community Fam Med 1: 121. doi: https://doi.org/10.15344/2456-3498/2016/121

2. MacDonald E N, Behar A, Wong W, Kunov H (2008) Noise exposure of opera musicians. Can Acoust 364: 11-16.

3. O'Brien I, Driscoll T, Bronwen A (2013) Sound exposure of professional orchestral musicians during solitary practice. J Acoust Soc Am 134: 27482754.

4. Jansen EJM, Helleman HW, Dreschler WA, de Laat JAPM (2009) Noise induced hearing loss and other hearing complaints among musicians of symphony orchestras. Int Arch Occup Environ Health 82: 153-164.

5. Qian CL, Behar A, Wong W (2011) Noise exposure of musicians of a ballet orchestra. Noise Health 13: 59-63.

6. Rodrigues MA, Freitas MA, Neves MP, Silva MV (2014) Evaluation of the noise exposure of symphonic orchestra musicians. Noise Health 16: 40-46.

7. Laitinen H, Poulsen T (2008) Questionnaire investigation of musicians' use of hearing protectors, self reported hearing disorders, and their experience of their working environment. Int J Audiol 47: 160-168.

8. Schink T, Kreutz G, Busch V, Pigeot I, Ahrens W (2014) Incidence and relative risk of hearing disorders in professional musicians. Occup Environ Med 71: 472-476.

9. Behar A, Wong W, Kunov $\mathrm{H}$ (2006) Risk of hearing loss in orchestra musicians: Review of the literature. Med Probl Perform Art 21: 164-168.

10. Emmerich E, Rudel L, Richter $F$ (2008) Is the audiologic status of professional musicians a reflection of the noise exposure in classical orchestral music? Eur Arch Otorhinolaryngol 265:753-758.

11. Schmidt JH, Pedersen ER, Juhl PM, Christensen-Dalsgaard J, Andersen TD, et al. (2011) Sound exposure of symphony orchestra musicians. Ann Occup Hyg 55: 893-905.

12. Mcllvaine D, Stewart M, Anderson R (2012) Noise exposure levels for musicians during rehearsal and performance times. Med Probl Perform Art 27: $31-36$

13. Russo FA, Behar A, Chasin M, Mosher S (2012) Noise exposure and hearing loss in classical orchestra musicians. Int J Ind Ergon 43: 474-478.

14. O'Brien I, Driscoll T, Ackermann B (2013) Sound exposure of professional orchestral musicians during solitary practice. J Acoust Soc Am 134: 27482754.

15. Niosh (2015) Reducing the risk of hearing disorders among musicians. By Kardous C, Themann C, Morata T, Reynolds J, Afanuh S, Cincinnati OH. U.S. Department of Health and Human Services, Centers for Disease Control and Prevention, National Institute for Occupational Safety and Health. DHHS (NIOSH) Publication No. 2015-184. 